\title{
Review of sustainable diets: are nutritional objectives and low-carbon-emission objectives compatible?
}

\section{Erica Doro ${ }^{1} \cdot$ Vincent Réquillart $^{2}$ (D)}

Received: 7 October 2019 / Accepted: 9 June 2020 / Published online: 8 July 2020

(C) The Author(s) 2020

\begin{abstract}
Food systems in developed countries face one major challenge, namely the promotion of diets that are both healthy and generate less greenhouse gas emissions (GHGE). In this article, we review papers evaluating the impact of a change in diets on both health and GHGE. We address the following questions: How big are the health and environmental impacts that could be induced by a switch to healthier diets? In monetary value, what is the relative importance of the health impact and the environmental impact? Is it possible to design an economic policy to increase global welfare that also takes into account the externalities on both health and the environment? Since the way the change in diet is modeled is a key issue, we classify papers according to the methodology used for simulating diet changes: ad hoc scenarios, optimized diets, and economic modeling. We find that it is possible to design economic policies that have positive impacts on both dimension. Because the substitutions/complementarities between food products are complex, it is not granted that a policy targeting one dimension will generate positive effects on the other dimensions. However, given the diversity of substitution and the complementarity possibilities between products, it is possible to design a policy that does improve both dimensions. A carbon-based tax policy that targets the products with a high greenhouse gas content (e.g., meat products) and reinvests the revenues collected with the tax to subsidize the consumption of fruit and vegetables, is likely to have positive effects on both dimensions.
\end{abstract}

Keywords Food $\cdot$ Consumer $\cdot$ Diets $\cdot$ Nutritional policy $\cdot$ Health $\cdot$ Climate change $\cdot$ Greenhouse gas $\cdot$ Environmental policy

JEL codes $\mathrm{I} 18 \cdot \mathrm{Q} 18 \cdot \mathrm{Q} 54$

Vincent Réquillart

vincent.requillart@tse-fr.eu

1 Toulouse School of Economics, University of Toulouse Capitole, 1 Esplanade de l'Université, 31000 Toulouse, France

2 Toulouse School of Economics, INRAE, University of Toulouse Capitole, 1 Esplanade de l’Université, 31000 Toulouse, France 


\section{Introduction}

It is now well recognized that low-quality diets are an important risk factor for contracting a non-communicable disease (WHO 2010). As a consequence, most developed countries have put in place nutritional policies that take various forms, such as healthy eating guidelines, information campaigns, food taxes, or food reformulation (e.g., Traill et al. 2013). Another important hurdle that countries face is climate change, which is linked to greenhouse gas emissions (GHGE) (IPCC 2013). According to recent estimates, food systems are responsible for 15 to $28 \%$ of the totality of GHGE in developed countries (Garnett 2011). To limit the increase in temperature to $2{ }^{\circ} \mathrm{C}$, ambitious reduction goals have been designed. For example, the European Commission set the target to cut GHGE by $40 \%$ in the European Union by 2030 , requiring a reduction in the emission burden represented by non-ETS (Emissions Trading System) sectors of $30 \%$, as compared with 2005. ${ }^{1}$ In the specific case of agriculture, the objective of reduction in 2030 is $20 \%$, as compared with 2005 . $^{2}$ Thus, food systems in developed countries face one particular major challenge, namely the promotion of diets that are both healthier and generate less GHGE.

There already exist some surveys in the literature addressing the compatibility between health and environmental goals. Joyce et al. (2014) focus on the link between dietary choices and GHGE. The main conclusion that emerges is that "diets containing a higher ratio of plant to animal products are generally associated with lower GHGE."

Auestad and Fulgoni (2015) address the relationship between dietary patterns and environmental sustainability. This survey reviews the impact of diets on various environmental indicators, including GHGE, land-use and water resources. From a methodological point of view, the authors highlight the importance of distinguishing the studies on the basis of the way in which changes in diet are modeled. Finally, the authors conclude (Auestad and Fulgoni 2015, p. 35) that "... shifts in eating patterns across the population occur slowly and the reduction potential in GHGE in developed countries may be greater in other sectors, such as transportation, rather than in the case of population-based shifts in eating patterns."

Hallstrom et al. (2015) study the impact of dietary changes on GHGE and land use. Their survey reveals that moving from the observed diet to a healthier diet, mostly based on dietary guidelines or on a partial substitution of meat with plant-based foods, is likely to lead to a reduction in GHGE in the range of 7-18\% (11 simulations over 14). Adopting a vegetarian diet allows a larger reduction in GHGE (in the range of 18$35 \%)^{3}$. The authors conclude that "the reduction potential seems mainly to depend on the amount and type of meat and animal products included in the diet ... the amount of red meat, and especially ruminant meat, seems to be a decisive parameter...". From this analysis, it appears that, unless diets radically change in the future, the reduction

\footnotetext{
${ }^{1}$ https://ec.europa.eu/clima/policies/strategies/2030 en. Accessed 20 June 2017.

${ }^{2}$ Refer to "A roadmap for moving to a competitive low carbon economy in 2050" Table 1. http://eur-lex. europa.eu/legal-content/EN/TXT/PDF/?uri=CELEX:52011DC0112\&from=EN.

The document also points out the importance of achieving the reduction of emissions in agriculture, as the importance of the latter in the overall EU emissions scenario will progressively increase as a consequence of higher reductions in other sectors.

${ }^{3}$ Finally, adopting a vegan diet would allow reducing GHGE to an even larger extent (range of 25-35\% in four studies over six, and about $50 \%$ in two studies).
} 
potential in GHGE through a change in consumer behavior exists, but is relatively limited, lower than the $20 \%$ reduction objective for agriculture.

Payne et al. (2016) investigate the link between low GHGE dietary patterns and health-related outcomes. They uncover significant heterogeneity in the results of the 100 dietary patterns reported in 16 studies. They confirm "an inconsistent relationship between reduced GHGE and positive health outcomes." For example, for the main macronutrients that need to be reduced (saturated fatty acids (SFA), salt, sugar), lower GHGE are more frequently associated with lower SFA intake, lower salt intake, but higher sugar intake. Finally, in most scenarios, they report "lower levels of essential micronutrients in lower GHGE diets."

Aleksandrowicz et al. (2016) review the environmental and health impact of dietary changes. They provide a comparison of the impact of 210 scenarios, classified into 14 groups, on GHGE, land use and water use. They point out that "health and environmental priorities may not always converge: for example, sugar may have low environmental impacts per calorie relative to other foods, and some fruit or vegetables may have higher GHGE per calorie than dairy and non-ruminant meats." Their overall conclusion is that, in high-income countries, the strategy "to reduce dietary-related environmental impacts should focus on reducing animal-based foods."

Perignon et al. (2017) focus on studies based on individual consumption. They review ten studies that they classify into two categories: "those that analyze the compatibility ... of environmental impact and nutritional quality, on the basis of subclasses of self-selected diets" and "those that identify the primary dietary contributors to environmental impacts of diets and then simulate the effect of their reduction on ... environmental indicators and nutritional quality." Analyzes based on subclasses of self-selected diets reveal that healthy diets are not systematically associated with low levels of GHGE. However, there exist diets consumed by a significant proportion of the population that are both healthy and generate less GHGE. From the set of simulation studies, it appears that the reduction in meat consumption is a potential driver of healthier diets and lower GHGE. This, however, depends on which foods are selected to replace meat. The survey also reveals the importance of energy intake, or its change, in the analysis of the relationship between health and GHGE.

In our view, an important drawback of the existing surveys is the absence of references to economic analyses. None of the above-cited surveys consider contributions from the economic literature. A significant part of our survey is, thus, devoted to review this economic literature and to compare its results with those extrapolated from other studies. There are at least three major aspects addressed in economic analysis that are worth developing further. The first is related to how consumer preferences are taken into account in their different approaches. The second refers to the evaluation of benefits, but also costs, that are associated with alternative scenarios or policies. The third consists of triggering a discussion on how to implement the desirable changes in practice; that is, to define an economic policy. Since, in this survey, we study the health and climate impacts of adopting modified diets, the issue of consumer preferences is central. To better understand the results and the limits of the alternative approaches developed in the literature, we propose a classification of the different approaches and discuss how to interpret their respective results. In particular, we distinguish papers in which the change in diet is defined by the modeler in an ad hoc manner from papers in which the change in diet results from a formal model. In the latter case, two classes of 
models are used. The first class of models, mainly developed by nutritionists, is based on mathematical programming. The model defines a new diet that integrates various nutritional and environmental constraints and minimizes an objective function that measures a departure from the current diet. The results are frequently designed as "optimized diets." The second class of models is based on the economic theory of rational consumers. Consumer preferences are summarized thanks to a matrix of elasticities that depicts how consumers react when facing a price change.

Based on this classification, we first present the main conclusions of each approach. That is, we provide a synthetic view of the impact on health and GHGE of modifying diets. In addition, we discuss the main advantages and weaknesses of the different approaches developed in the literature. Then, based on insights from the economic analysis, we address the following complementary questions: How big are the health and environmental impacts that could be induced by a switch to healthier diets? What is, in monetary value, the relative importance of the health impact and the environmental impact? How is it possible to design an economic policy that increases global welfare, taking into account externalities on both health and the environment?

Our main conclusions can be summarized as follows. Approaches based on ad hoc changes in diet or optimized diets show that adopting healthier diets might be accompanied by a reduction in GHGE, but this is not systematic. They also reveal that diets with a lower impact on climate might also be healthier, but this is not systematic. Economic models show that carbon-based taxes lower the impact of diets on climate, but might have negative impacts on health. They also demonstrate that it is possible to design policies that lead to improvements in both dimensions. Roughly, a carbon-based tax policy that targets the products with a high greenhouse gas (GHG) content (e.g., meat products), and reinvests the revenues collected with the tax to subsidize the consumption of fruit and vegetables, is likely to have positive effects on both dimensions.

The paper is organized as follows. "Selection and classification of papers" covers the selection and classification of papers that are included in the survey. "The effect of ad hoc changes in diet on GHGE and health," "The effect of optimized diets on GHGE," and "Impact of economic policies on health and GHGE" provide the main results for the three different categories of studies: "The effect of ad hoc changes in diet on GHGE and health" deals with the studies based on ad hoc changes of diets, "The effect of optimized diets on GHGE" with the studies based on optimized diets, and "Impact of economic policies on health and GHGE" discusses in detail the impact of economic policies on health and GHGE. "Comparison of health and climate benefits" compares the health and the GHGE benefits. Finally, "Conclusion: research needs and policy perspectives" concludes.

\section{Selection and classification of papers}

\section{Selection of papers}

We use two methods to select the papers included in this survey. For "non-economic" papers, we mainly use the reference section of the existing surveys. As these papers have already been reviewed in different surveys, we use them to provide a comparison 
with papers from the economic literature. ${ }^{4} \mathrm{We}$ also use them to discuss various methodological issues and shed light on important results. Moreover, since our goal is to analyze the impact that changes in diet have on health and GHGE, we do not include papers evaluating the link between the healthiness and the associated GHGE of observed diets within the population (referred as self-selected diets in the literature). ${ }^{5}$ For economic papers, we search all EconLit papers for those containing the following words: "greenhouse" OR "GHG" OR "carbon" OR "CO 2 " AND "health" AND "food" OR "diet." In both cases, we also use the reference section of the selected papers, particularly the most recent ones, to check for any omission. To be included in this survey, the papers all meet the following criteria: (i) they are published in peerreviewed journals between 2009 and December 2018; (ii) the analysis concerns EU countries $^{6}$; (iii) the analysis encompasses the entire diet in order to consider substitutions between food products; (iv) quantitative estimates of the impact of a change in diet on GHGE are provided; and (v) estimates of the impact of a change in diet on health or on health-related indicators are provided. The choice of the articles that meet the inclusion criteria is based on the information available in the title and in the abstract.

\section{General modeling approach}

The all-encompassing approach that deals with the impact on health and GHGE of changes in diet combines different models as follows:

- A first model predicts the change in diet. Mathematically, the model defines $\Delta X=\left(\Delta X_{1}, \ldots, \Delta X_{i}, \ldots, \Delta X_{n}\right)$ as the vector of variation of intake of the $n$ food products. The change in diet is either imposed by the modeler in an ad hoc manner or results from a formal model, which evaluates the impact of alternative scenarios on the diet. In the latter case, two classes of models are implemented. The first class of models, mainly developed by nutritionists, is based on mathematical programming. The results are frequently designed as "optimized diets." The second class of models is based on the economic theory of rational consumers. Consumer preferences are summarized thanks to a matrix of elasticities that depicts how consumers react when facing a price change;

- From the change in diet, more or less sophisticated models are used to assess the health impact. At the very minimum, based on the nutrient content of food products, the change in diet is translated into a change in nutrient intake. Denoting $N$ the $(n, m)$ matrix of the content in $m$ nutrients of the $n$ food products, $\Delta N=\left(\Delta N_{1}\right.$, $\ldots, \Delta N_{i}, \ldots, \Delta N_{m}$ ) the vector of variation of intake of the $m$ nutrients associated with the change in diet, we have $\Delta N=\Delta X \cdot N$. From this change in nutrient intake, in some papers, a health impact is deduced thanks to some epidemiological models that link the change in nutrient intakes to a change in the incidence of some diseases;

- From the change in diet, the impact on GHGE is computed taking into account the GHG content of each product. The GHG content is based, in most cases, on life-

\footnotetext{
${ }^{4}$ This explains why we select these papers using the existing surveys.

${ }^{5}$ The reader should refer to the review by Perignon et al. (2017) to have a synthesis of those papers.

${ }^{6}$ If the literature displays some regularities, country-specific characteristics often have an impact on the results, which justifies our focus on a specific set of countries.
} 
cycle analyses. ${ }^{7}$ Formally, denoting $E=E_{1}, \ldots, E_{i}, \ldots, E_{n}$ the vector of GHG content of the food products, and $\Delta G$ the change in GHGE associated with the change in diet, we have $\Delta G=\Delta X \cdot E^{t}$.

\section{Classification of papers}

Based on the way the diet change is modeled, we propose a classification of the papers included in the survey. Table 1 lists the set of papers according to this classification and indicates whether or not they have been included in the previous surveys. We distinguish three groups of papers. The first, denominated "Ad hoc changes in diet" gathers papers in which changes in diet are directly decided by the modeler. That is, the modeler defines which products are substituted by other products. In some cases, the final diet is defined according to nutritional recommendations. In this case, the modeler defines the composition of a diet that is nutritionally adequate. The second, denominated "optimized diets" gathers papers in which an optimization model is designed to determine an optimal diet. The general idea of the approach is to minimize an objective function, subject to various constraints. The function to be optimized varies between studies. It is frequent that this objective function is a distance function between the observed diet and the modeled diet. These models frequently integrate nutritional constraints (i.e., dietary requirements), thus ensuring the nutritional adequacy of the optimized diet. They can also integrate environmental constraints (e.g., a maximum for GHGE). As opposed to the ad hoc changes in diet set of papers, the proposed changes in diet are the results of a mathematical model. The critical issue is, then, the definition of the main elements of the model, that is the definition of the objective function as well as the relevant constraints that are included in the model. Finally, the third, denominated "Economic analysis," gathers papers that rely on economic theory. In this group, changes in diet are evaluated thanks to an economic model that rests on the theory of rationale consumers. In particular, the model is based on estimates of price elasticities, in most cases own-price and cross-price elasticities, which summarize how consumers react to price changes. Different types of models are used, but with in common the use of elasticities to infer how consumers react to economic policies.

\section{The effect of ad hoc changes in diet on GHGE and health}

Among the studies within the category ad hoc changes in diet, we only keep those assuming an isocaloric change. Thus, with reference to this group of papers already reviewed in different surveys, we aim to answer two specific questions. The first involves detecting the type of substitution leading to both better health and lower GHGE. The second refers to determining an order of magnitude of the impact of adopting a healthier diet on GHGE. Since, in this methodological approach, the type of substitution is decided by the modeler and does not result from an in-depth analysis of

${ }^{7}$ For a more detailed discussion on the issues related to the GHG content of products, refer to Hallstrom et al. (2015). 
Table 1 Classification of papers reviewed in this survey and comparison with the subset of papers evaluating the healthiness and GHGE of European diets reviewed in previously published surveys

\begin{tabular}{|c|c|c|c|c|c|c|c|}
\hline Authors & Country & $\begin{array}{l}\text { Joyce } \\
\text { et al. } \\
\text { (2014) }\end{array}$ & $\begin{array}{l}\text { Auestad and } \\
\text { Fulgoni (2015) }\end{array}$ & $\begin{array}{l}\text { Hallstrom } \\
\text { et al. } \\
(2015)\end{array}$ & $\begin{array}{l}\text { Payne } \\
\text { et al. } \\
(2016)\end{array}$ & $\begin{array}{l}\text { Aleksandrowicz } \\
\text { et al. }{ }^{\text {a }}(2016)\end{array}$ & $\begin{array}{l}\text { Perignon } \\
\text { et al. } \\
(2017)\end{array}$ \\
\hline
\end{tabular}

Ad hoc changes in diet

\begin{tabular}{|c|c|c|c|c|c|}
\hline $\begin{array}{l}\text { Risku-Norja } \\
\text { et al. (2009) }\end{array}$ & FIN & $\mathrm{X}$ & $\mathrm{X}$ & $\mathrm{X}$ & \\
\hline $\begin{array}{l}\text { Tukker et al. } \\
\text { (2011) }\end{array}$ & EU & $\mathrm{X}$ & $\mathrm{X}$ & $\mathrm{X}$ & $\mathrm{X}$ \\
\hline $\begin{array}{l}\text { Scarborough } \\
\text { et al. (2012) }\end{array}$ & UK & & & & \\
\hline $\begin{array}{l}\text { Vieux et al. } \\
\text { (2012) }\end{array}$ & $\mathrm{F}$ & $\mathrm{X}$ & $\mathrm{X}$ & $\mathrm{X}$ & \\
\hline $\begin{array}{l}\text { Hoolohan et al. } \\
\text { (2013) }\end{array}$ & UK & $\mathrm{X}$ & & $\mathrm{X}$ & $\mathrm{X}$ \\
\hline $\begin{array}{l}\text { Meier and } \\
\text { Christen } \\
(2013)\end{array}$ & $\mathrm{D}$ & $\mathrm{X}$ & $\mathrm{X}$ & $\mathrm{X}$ & $\mathrm{X}$ \\
\hline Saxe et al. (2013) & $\mathrm{DK}$ & $\mathrm{X}$ & $\mathrm{X}$ & $\mathrm{X}$ & \\
\hline $\begin{array}{l}\text { van Dooren et al. } \\
\text { (2014) }\end{array}$ & NL & $X$ & & $X$ & $\mathrm{X}$ \\
\hline $\begin{array}{l}\text { Westhoek et al. } \\
\text { (2014) }\end{array}$ & EU & $\mathrm{X}$ & & & \\
\hline $\begin{array}{l}\text { Roos et al. } \\
\text { (2015) }\end{array}$ & SW & & & & \\
\hline \multicolumn{6}{|l|}{ Optimized diets } \\
\hline $\begin{array}{l}\text { Macdiarmid } \\
\text { et al. (2012) }\end{array}$ & UK & $\mathrm{X}$ & $\mathrm{X}$ & $\mathrm{X}$ & \\
\hline $\begin{array}{l}\text { Green et al. } \\
(2015)^{\mathrm{b}}\end{array}$ & UK & & & & $\mathrm{X}$ \\
\hline $\begin{array}{l}\text { Perignon et al. } \\
\text { (2016) }\end{array}$ & $\mathrm{F}$ & & & & \\
\hline $\begin{array}{r}\text { van Dooren and } \\
\text { Aiking (2016) }\end{array}$ & NL & & & & \\
\hline $\begin{array}{l}\text { Horgan et al. } \\
\text { (2016) }\end{array}$ & UK & & & & \\
\hline $\begin{array}{l}\text { Vieux et al. } \\
\text { (2018) }\end{array}$ & $\mathrm{EU}$ & & & & \\
\hline
\end{tabular}

\section{Economic analyses}

\begin{tabular}{|c|c|c|}
\hline $\begin{array}{l}\text { Briggs et al. } \\
\quad(2013)\end{array}$ & UK & $\mathrm{X}$ \\
\hline $\begin{array}{l}\text { Edjabou and } \\
\text { Smed (2013) }\end{array}$ & DK & \\
\hline $\begin{array}{l}\text { Abadie et al. } \\
\text { (2016) }\end{array}$ & $\mathrm{N}$ & \\
\hline $\begin{array}{l}\text { Caillavet et al. } \\
\text { (2016) }\end{array}$ & $\mathrm{F}$ & \\
\hline
\end{tabular}


Table 1 (continued)

\begin{tabular}{|c|c|c|c|c|c|c|c|}
\hline Authors & Country & $\begin{array}{l}\text { Joyce } \\
\text { et al. } \\
(2014)\end{array}$ & $\begin{array}{l}\text { Auestad and } \\
\text { Fulgoni (2015) }\end{array}$ & $\begin{array}{l}\text { Hallstrom } \\
\text { et al. } \\
(2015)\end{array}$ & $\begin{array}{l}\text { Payne } \\
\text { et al. } \\
(2016)\end{array}$ & $\begin{array}{l}\text { Aleksandrowicz } \\
\text { et al. }{ }^{\text {a }}(2016)\end{array}$ & $\begin{array}{l}\text { Perignon } \\
\text { et al. } \\
(2017)\end{array}$ \\
\hline
\end{tabular}

$\begin{array}{lll}\text { Irz et al. (2016) } & \text { F } & \text { X } \\ \begin{array}{c}\text { Springmann } \\ \text { et al. (2016b)c }\end{array} & \text { W } & \\ \begin{array}{c}\text { Garcia-Muros } \\ \text { et al. (2017) }\end{array} & \text { E } \\ \begin{array}{c}\text { Bonnet et al. } \\ \text { (2018) }\end{array} & \text { F }\end{array}$

\footnotetext{
a Briggs et al. (2013) and Edjabou and Smed (2013) papers are cited but not used in the survey

${ }^{b}$ Milner et al. (2015) provide additional information on the health impact of scenarios. Method and scenarios are identical to those developed in Green et al. (2015)

${ }^{\mathrm{c}} \mathrm{W}$ stands for World. However, this paper provides some results for Europe
}

consumer behavior, we do not want to let the analysis be affected by a scale issue. In other words, reducing the amount of calories consumed (which is frequently recommended by nutritionists, but difficult to put into practice by consumers) would automatically lead to lower GHGE. By keeping the calorie intake constant, we only consider the impact of substitutions between food products. We, thus, abstract from a change in calories that is a consequence of consumer choices and that, as such, should be determined in models that explicitly integrate consumer behavior, that is, models based on the modeling of consumer choices.

A set of papers focuses on the impact of adopting dietary recommendations. ${ }^{8}$ In Table 2, we report the change in GHGE associated with the adoption of nutritional recommendations, assuming no change in calorie intake. Overall, the results suggest that adopting dietary recommendations is likely to be accompanied by a decrease in GHGE in the range of $8-26 \%$ (average, $-13 \%$ ). According to these studies, there is compatibility between health and environmental objectives. Interestingly, Tukker et al. (2011) explore two scenarios of recommendations. When recommendations do not include a limit in red meat consumption, then the impact on GHGE of adopting healthy recommendations is positive $(+1.2 \%) .^{9}$ This result, which is in line with most research analyzing the impact on GHGE of ad hoc changes in diet, shows the importance of replacing meat products with plantbased alternatives within the scope of lowering GHGE. Finally, Roos et al. (2015) report a $26 \%$ decrease in GHGE, certainly due to a large decrease in meat products and an increase in grains and potatoes. An obvious limitation of this approach is to assume that consumers will comply with the nutritional recommendations. In the case of France, Estaquio (2011) studies the adherence by consumers to the nutritional recommendations defined in the "Plan National Nutrition Sante." She shows that some recommendations are poorly met by consumers. For example, less than $10 \%$ of men have an adequate intake of salt, and

\footnotetext{
${ }^{8}$ In these papers, the health effect of adopting dietary recommendations is not evaluated but can be assumed to be positive in line with the objective of the recommendations.

${ }^{9}$ Note that the definition of red meat differs among studies. Tukker et al. (2011) include pork in the red meat category, which is not the case in some other studies.
} 
Table 2 The impact of adopting dietary recommendations on GHGE

\begin{tabular}{llllll}
\hline Authors & Country & $\begin{array}{l}\text { Number } \\
\text { of products }\end{array}$ & $\begin{array}{l}\text { GHGE baseline } \\
\text { (t/person/year) }\end{array}$ & $\begin{array}{l}\text { Change in } \\
\text { GHGE (\%) }\end{array}$ & $\begin{array}{l}\text { Change in meat } \\
\text { intake (\%) }\end{array}$ \\
\hline Risku-Norja et al. (2009) & FIN & 24 & 1.7 & -16 & -38 \\
Tukker et al. (2011)b & EU & 21 & 2.6 & -8 & n.a. \\
Meier and Christen (2013) & D & 43 & 2.1 & -11 & -38 \\
Saxe et al. (2013) & DK & 30 & 1.9 & -8 & -18 \\
van Dooren et al. (2014) & NL & 17 & 1.5 & -12 & -21 \\
Roos et al. (2015) & SW & 18 & 1.9 & -26 & n.a. \\
\hline
\end{tabular}

n.a., not available

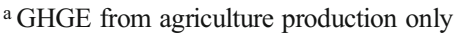

b Scenario 2 with recommendations including a constraint on beef, lamb, and pork meat

c The study concerns women only

$36 \%$ have an adequate intake of milk and dairy products. She also ascertains that elderly people and women tend to better comply with the recommendations.

A second subgroup of papers analyzes the impact on health and GHGE of predetermined substitutions. All studies simulate a substitution, at a constant energy intake, of a set of animal products with a few alternatives (Table 3). The alternatives are either other animal products (substitution within the category) or plant products (substitution between categories). The health impact is evaluated using different indicators. Only one study (Scarborough et al. 2012) evaluates the impact on health on the basis of the number of deaths avoided (DA). Other studies provide the change in some nutrients or in an indicator of diet quality. ${ }^{10}$ Simulations show that it is possible to design substitutions that lead to improvements in both health and the climate. Briefly summarized, the different studies reveal that: ${ }^{11}$

- Replacing part of meat and dairy products with cereals (or a mix of cereals and fruit and vegetables $(\mathrm{F} \& \mathrm{~V}))$ leads to significant improvements in both dimensions;

- Replacing white meat with cereals (or a mix of cereals and F\&V) leads to improvements in both dimensions, but to a lower extent than in the previous case;

- Replacing red meat with white meat reduces GHGE. The aggregate health impact seems positive, although some adverse effects are envisioned;

- When substitution involves mostly $\mathrm{F} \& \mathrm{~V}$, the health impact is positive, although it might be possible that, in some cases, GHGE increase. This is a consequence of the low caloric content of $\mathrm{F} \& \mathrm{~V}$, in a context in which substitutions are decided on the basis of food calories. Thus, F\&V have a low GHG content when evaluated per kilo of product, but result in higher emissions if evaluated per calorie of product;

\footnotetext{
${ }^{10}$ Vieux et al. (2012) focus on the change in the energy density of the diet. A priori, a decrease in energy density indicates an healthier diet.

${ }^{11}$ For a more extensive view, refer to the different surveys mentioned in Table 1.
} 
Table 3 Impact of ad hoc changes on GHGE and health

\begin{tabular}{|c|c|c|c|c|}
\hline Authors & Country & Scenarios & Health effect & $\begin{array}{l}\text { Change } \\
\text { in GHGE }(\%)\end{array}$ \\
\hline \multirow[t]{6}{*}{$\begin{array}{l}\text { Scarborough et al. } \\
\text { (2012) }\end{array}$} & \multirow[t]{6}{*}{ UK } & $\begin{array}{l}\mathrm{S} 1,-50 \% \text { meat and dairy } \\
\text { products }\end{array}$ & $36,910 \mathrm{DA}$ & \multirow[t]{2}{*}{-19} \\
\hline & & replaced by cereals and $F \& V$ & $(30192-43,592)$ & \\
\hline & & $\mathrm{S} 2,-75 \%$ red meat & 1999 DA & \multirow[t]{2}{*}{-9} \\
\hline & & replaced by white meat & $(1739-2389)$ & \\
\hline & & $\mathrm{S} 3,-50 \%$ white meat & 9297 DA & \multirow[t]{2}{*}{-3} \\
\hline & & replaced by cereals and $\mathrm{F} \& \mathrm{~V}$ & $(7288-11,301)$ & \\
\hline \multirow[t]{7}{*}{$\begin{array}{l}\text { Vieux et al. } \\
\text { (2012) }\end{array}$} & \multirow[t]{7}{*}{$\mathrm{F}$} & $\begin{array}{l}\mathrm{S} 3,-20 \% \text { meat and/or deli } \\
\text { meat replaced by F\&V }\end{array}$ & $-13 \%(\mathrm{ED})$ & 0 \\
\hline & & replaced by dairy & $-9 \%(\mathrm{ED})$ & -1.7 \\
\hline & & replaced by mixed dishes & $-8 \%(\mathrm{ED})$ & -2.8 \\
\hline & & $\begin{array}{l}\mathrm{S} 4, \max 50 \mathrm{~g} \text { meat and no } \\
\text { deli meat }\end{array}$ & & \\
\hline & & replaced by F\&V & $-27 \%(\mathrm{ED})$ & +2.7 \\
\hline & & replaced by dairy & $-17 \%(\mathrm{ED})$ & -3.5 \\
\hline & & replaced by mixed dishes & $-14 \%(\mathrm{ED})$ & -7.2 \\
\hline \multirow{2}{*}{$\begin{array}{l}\text { Hoolohan et al. } \\
\text { (2013) }\end{array}$} & \multirow[t]{2}{*}{ UK } & $-100 \%$ red meat & $+5 \%$ protein & \multirow[t]{2}{*}{-18} \\
\hline & & replaced by white meat & $\begin{array}{l}0 \% \text { carbs, }+9 \% \\
\quad \text { salt }\end{array}$ & \\
\hline \multirow{4}{*}{$\begin{array}{l}\text { Westhoek et al. } \\
\text { (2014) }\end{array}$} & \multirow[t]{4}{*}{$\mathrm{EU}$} & Cereals replace & & \\
\hline & & $50 \%$ beef and dairy & $-27 \%(\mathrm{SFA})$ & $-14(-38)^{\mathrm{a}}$ \\
\hline & & $50 \%$ pig and poultry & $-17 \%$ (SFA) & $-5(-5)^{\mathrm{a}}$ \\
\hline & & $50 \%$ meat and dairy & $-14 \%(\mathrm{SFA})$ & $-19 \%(-42)^{\mathrm{a}}$ \\
\hline
\end{tabular}

Note: we only use the subset of scenarios analyzed in these papers that fit our requirements

${ }^{a}$ Greening scenario, which assumes that arable land previously used in the production of animal feed is converted into perennial bio-energy crops

- Some studies demonstrate that there exist trade-offs between health objectives and GHGE objectives. A larger improvement in one dimension is accompanied by a lower improvement in the other;

- The study by Westhoek et al. (2014) suggests that land use change is an important aspect. For example, when cereals replace 50\% of beef and dairy, GHGE are reduced by $14 \%$ without taking into account land use change and by $38 \%$ when land use change is considered. In their analysis, they adopt a GHGE favorable view, as they assume that the land, made available through the substitution of cereals for animal products, is used to produce bioenergy crops. However, this result suggests that taking into account land use change might improve the climate impact of modifying diets, a subject that is extensively addressed in the "Conclusion: research needs and policy perspectives" section;

- Overall, even with rather large substitutions in diet, the change in GHGE remains rather modest (from +3 to $-19 \%$ ) as compared with the EU objective to cut GHGE from food chains by $30 \%$ by 2030 . 


\section{The effect of optimized diets on GHGE}

Rather than defining a priori the substitution between food products, some studies are based on optimization techniques. The general idea is to minimize an objective function, subject to various constraints. In particular, these models integrate nutritional constraints (i.e., dietary requirements), thus ensuring the nutritional adequacy of the optimized diet.

Depending on the study, the objective function differs. Macdiarmid et al. (2012) minimize the GHGE resulting from the diet; Perignon et al. (2016), Vieux et al. (2018), Green et al. (2015), and van Dooren and Aiking (2016) minimize a distance function between the observed diet and the modeled diet. By minimizing a distance function, these studies introduce the idea that consumers seek to modify their diet (at the very least) when complying with some constraints. This represents a first attempt to integrate consumer behavior into the picture. Thus, van Dooren and Aiking (2016) minimize the absolute changes in terms of portions. Perignon et al. (2016) define the distance function as the sum of the absolute values of the relative deviation of each product and each food group. ${ }^{12}$ In this setting, modifying by, say, $10 \%$ the consumption of a food product that is marginal in the diet has the same "cost" as modifying by $10 \%$ the consumption of a food product that is consumed in important quantities. Moreover, all food products are considered equally, in that the model does not integrate consumer preferences for the different food products.

Alternatively, the distance function defined by Green et al. (2015) integrates some concepts arising from the economic theory of the rational consumer. In this case, the distance is given by the weighted sum of the squared relative deviation of each food product. The weight is given by the ratio of the share of expenditure of a product divided by its own price elasticity. The idea of a weight inversely proportional to its own-price elasticity can be traced back to the taxation theory (e.g., Samuelson 1951). However, as shown by Irz et al. (2015), in the case of nutritional recommendations, it is more complex to take into account consumer preferences, as they are related to own- and cross-price elasticities defining the substitutability and complementarity relationships between products. The above-detailed literature provides the following results (Table 4):

- Satisfying nutritional constraints might lead to significant changes in GHGE. The results appear to be country and gender specific. Using the same model for five countries, Vieux et al. (2018) find medium to large increases in GHGE in most cases (seven cases over 10) and small or intermediate decreases in a few cases (three cases over 10). For instance, in the UK, they find an increase in GHGE for men $(+31 \%)$ and a decrease for women $(-8 \%)$. Instead, Green et al. (2015), who use a slightly different objective function, find a reduction of $17 \%$ in GHGE for women;

- Satisfying nutritional constraints implies significant changes in diet. In particular, this implies an increase in the consumption of F\&V, cereal products, and, at least in some countries, a decrease in the consumption of meat products;

- Once nutritional constraints are satisfied, imposing an upper boundary on GHGE results in a reduction in animal product consumption, sometimes in significant proportions;

\footnotetext{
${ }^{12}$ Vieux et al. (2018) use a similar objective function: the distance function is defined as the sum of the absolute values of the relative deviation for each product.
} 
Table 4 The effect of optimized diets on GHGE and the composition of the diet

\begin{tabular}{|c|c|c|c|c|}
\hline Authors & Country & $\begin{array}{l}\text { Number } \\
\text { of food } \\
\text { products }\end{array}$ & Method & Main results \\
\hline \multirow{4}{*}{$\begin{array}{l}\text { Macdiarmid } \\
\text { et al. } \\
(2012)^{\mathrm{a}}\end{array}$} & \multirow[t]{4}{*}{ UK } & \multirow[t]{4}{*}{82} & Min GHGE & GHGE, $-36 \%$ \\
\hline & & & Subject to & $\begin{array}{l}\text { Increase: } \mathrm{F} \& \mathrm{~V} \text { (about } 15 \%) \text {, cereals, } \\
\text { potatoes (about }+40 \%)\end{array}$ \\
\hline & & & - Nutritional constraints & $\begin{array}{l}\text { Decrease high fat, sugar (about } \\
-50 \% \text { ), meat (about }-50 \%)\end{array}$ \\
\hline & & & - Acceptability constraints & $\begin{array}{l}\text { Modify the type of dairy products } \\
\text { (increase drinking milk, decrease fat } \\
\text { products) }\end{array}$ \\
\hline \multirow{9}{*}{$\begin{array}{l}\text { Green et al. } \\
\text { (2015) }\end{array}$} & \multirow[t]{9}{*}{ UK } & \multirow[t]{9}{*}{42} & Min changes in diet & $\mathrm{GHGE},-17 \%$ \\
\hline & & & Subject to & Increase: cereals, F\&V \\
\hline & & & - Nutritional constraints & $\begin{array}{l}\text { Decrease: red meat, dairy products, } \\
\text { eggs, soft drinks }\end{array}$ \\
\hline & & & \multirow[t]{6}{*}{ - GHGE constraints } & GHGE, -20 to $-30 \%$ \\
\hline & & & & $\begin{array}{l}\text { Only small additional changes } \\
\text { compared with healthy diet }\end{array}$ \\
\hline & & & & GHGE, $-40 \%$ \\
\hline & & & & Decrease meat, dairy, fruits \\
\hline & & & & Increase sugary snacks \\
\hline & & & & $\begin{array}{l}\text { GHGE: reductions of GHGE }>40 \% \\
\text { involve major dietary changes }\end{array}$ \\
\hline \multirow{4}{*}{$\begin{array}{l}\text { Van Dooren } \\
\text { and Aiking } \\
(2016)\end{array}$} & \multirow[t]{4}{*}{ NL } & \multirow[t]{4}{*}{206} & Min changes in diet & Optimized “LLD” scenario: \\
\hline & & & Subject to & GHGE, $-20 \%$ \\
\hline & & & - Nutritional constraints & $\begin{array}{l}\text { Increase: } F \& V(+19 \%), \text { fruits } \\
\quad(+91 \%), \text { legumes }(+183 \%), \text { fish } \\
\quad(+48 \%)\end{array}$ \\
\hline & & & - GHGE constraints & $\begin{array}{l}\text { Decrease: meat }(-13 \%) \text {, cheese } \\
\quad(-100 \%)\end{array}$ \\
\hline \multirow[t]{4}{*}{$\begin{array}{l}\text { Horgan et al. } \\
\qquad(2016)\end{array}$} & \multirow[t]{4}{*}{ UK } & \multirow[t]{4}{*}{134} & Min changes in diet & $\begin{array}{l}\text { Healthy diet scenario (nutritional } \\
\text { recommendations) }\end{array}$ \\
\hline & & & Subject to & GHGE, $-15 \%$ \\
\hline & & & - Nutritional constraints & $\begin{array}{l}\text { Sustainable diet scenario (both } \\
\text { nutritional and environmental } \\
\text { constraints) }\end{array}$ \\
\hline & & & - GHGE constraints & GHGE, $-27 \%$ \\
\hline \multirow[t]{5}{*}{$\begin{array}{l}\text { Perignon et al. } \\
\text { (2016) }\end{array}$} & \multirow[t]{5}{*}{$\mathrm{F}$} & \multirow[t]{5}{*}{402} & Min changes in diet & $\begin{array}{l}\text { "FREE" scenario (no nutritional } \\
\text { constraints) }\end{array}$ \\
\hline & & & Subject to & $\begin{array}{l}\text { GHGE, }-30 \% \text { reduction is possible } \\
\text { without significant impact on diet } \\
\text { quality }\end{array}$ \\
\hline & & & - Acceptability constraints & Food product changes are not reported \\
\hline & & & - GHGE constraints & \\
\hline & & & - Nutritional constraints & \\
\hline
\end{tabular}


Table 4 (continued)

\begin{tabular}{lll}
\hline Authors Country & $\begin{array}{l}\text { Number Method } \\
\text { of food } \\
\text { products }\end{array}$
\end{tabular}

Vieux et al. F, Fin, I, $151 \quad$ Min changes in diet (2018)

Sw, UK Subject to

- Acceptability constraints

- Nutritional constraints

- GHGE constraints
“ADEQ” scenario (includes nutritional constraints and no increase in GHGE)

Significant changes within the food categories:

Increase $\mathrm{F} \& \mathrm{~V}$ (+30 to $+40 \%$ ), breakfast cereals $(+250 \%)$, fish $(+75 \%)$

Decrease: deli meat $(-75 \%)$, ruminant meat $(-25 \%)$, cheese $(-50 \%)$

With nutritional constraints, decreasing GHGE by 20 to $30 \%$ is possible without additional large changes in the diet

Larger GHGE reductions ( $>40 \%$ ) lead to larger decrease (or removal) of meat and of animal-based dishes

"NUTR" scenario (no GHGE constraint):

Mostly increase in GHGE. Depending on the country, from -3 to $+31 \%$ for men, from -8 to $+46 \%$ for women.

Decrease in sweetened and fat products

Increase in $\mathrm{F} \& \mathrm{~V}$, starchy foods

Within food group substitutions needed

Changes in animal-based products but country-specific changes

Reduction of GHGE by $30 \%$ is possible without large additional changes (compared with nutritional constraints alone)

a Percentage changes in food product consumption are approximated from the results presented on p. 637 of the paper

- Once nutritional constraints are satisfied, imposing reductions in GHGE in the range of -20 to $-30 \%$ is possible without large additional changes in the diet;

- There exist possibilities to improve both the health and the climate dimensions through a change in diets;

- It is possible to cut diet-related GHGE, without negatively impacting the diet quality. 
Studies using this methodology suggest that significant reductions in GHGE are possible $(-20$ to $-30 \%)$ and compatible with health objectives, as diets satisfy nutritional constraints in this setting. Thus, the results suggest that there exist combinations of food products allowing the reduction of GHGE from diets and, at the same time, improving the healthiness of diets. However, this general result depends on significant changes in the diet at both the food group level and the individual product level. For example, Vieux et al. (2018) report that required changes concern 1.5 to $2 \mathrm{~kg}$ of food per day for women. This is a significant change in diet, considering that the initial food intake is between 2 and $3 \mathrm{~kg} /$ day depending on the country. Moreover, as shown by Horgan et al. (2016), who develop a similar analysis at the individual level, there is a large heterogeneity across changes in diet that are required to achieve healthier and more environmentally friendly dietary patterns. Finally, as compared with the results discussed in "The effect of ad hoc changes in diet on GHGE and health," it is possible to reach larger reductions in GHGE while complying with nutritional recommendations. This is directly linked to the fact that a large number of food products is taken into consideration, which makes it possible to design more diverse diets and demonstrates that it is theoretically reasonable to significantly decrease GHGE.

With all of this taken into account, an interesting feature of this approach is that it allows us to consider a large number of food products. As a consequence, one can analyze substitutions between product categories, as well as substitutions within product categories. However, the key issue behind these results is related to the likelihood of such changes in practice. Therefore, the pivotal question to be investigated remains the plausibility of such changes. Since these approaches do not properly take consumer preferences into account, their results should be interpreted cautiously. Finally, another weakness is the absence of tools providing incentives for consumers to significantly change their diets.

In the following section, we provide a detailed analysis of the economic studies addressing these two weaknesses: giving more attention to consumer preferences and simulating the impact of economic tools promoting changes in consumer food choices.

\section{Impact of economic policies on health and GHGE}

Rather than simulating more (or less) realistic changes in diet and exploring their potential effects in terms of health and reductions in GHGE, economists evaluate how consumers are likely to react to policy scenarios in order to infer the implications of these changes on diet quality, health and GHGE. We found eight published papers evaluating the impact of policies in the European context (see Table 5). ${ }^{13}$ Only one paper addresses the impact of policy recommendations, whereas the others analyze price policies. In this latter case, taxes and subsidies are frequently based on the GHG content of the food products. Most papers consider the whole diet, distinguishing about 20-25 different food products. In most cases, elasticities are estimated using the AIDS demand model. Given the level of

\footnotetext{
${ }^{13}$ One paper (Springmann et al. 2016b) develops an analysis at the world level; we use the results related to the developed countries in the "Conclusion: research needs and policy perspectives" section.
} 


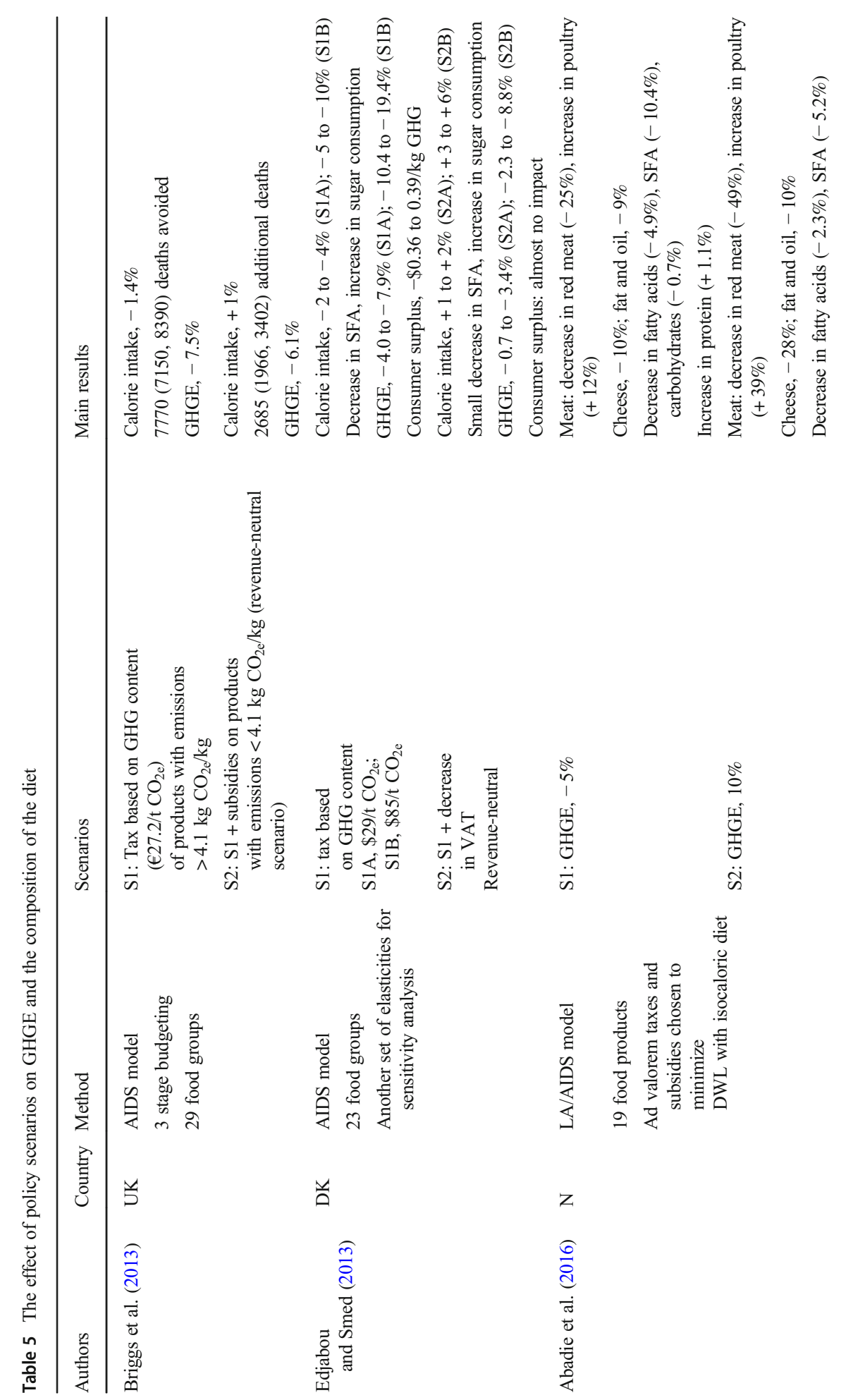




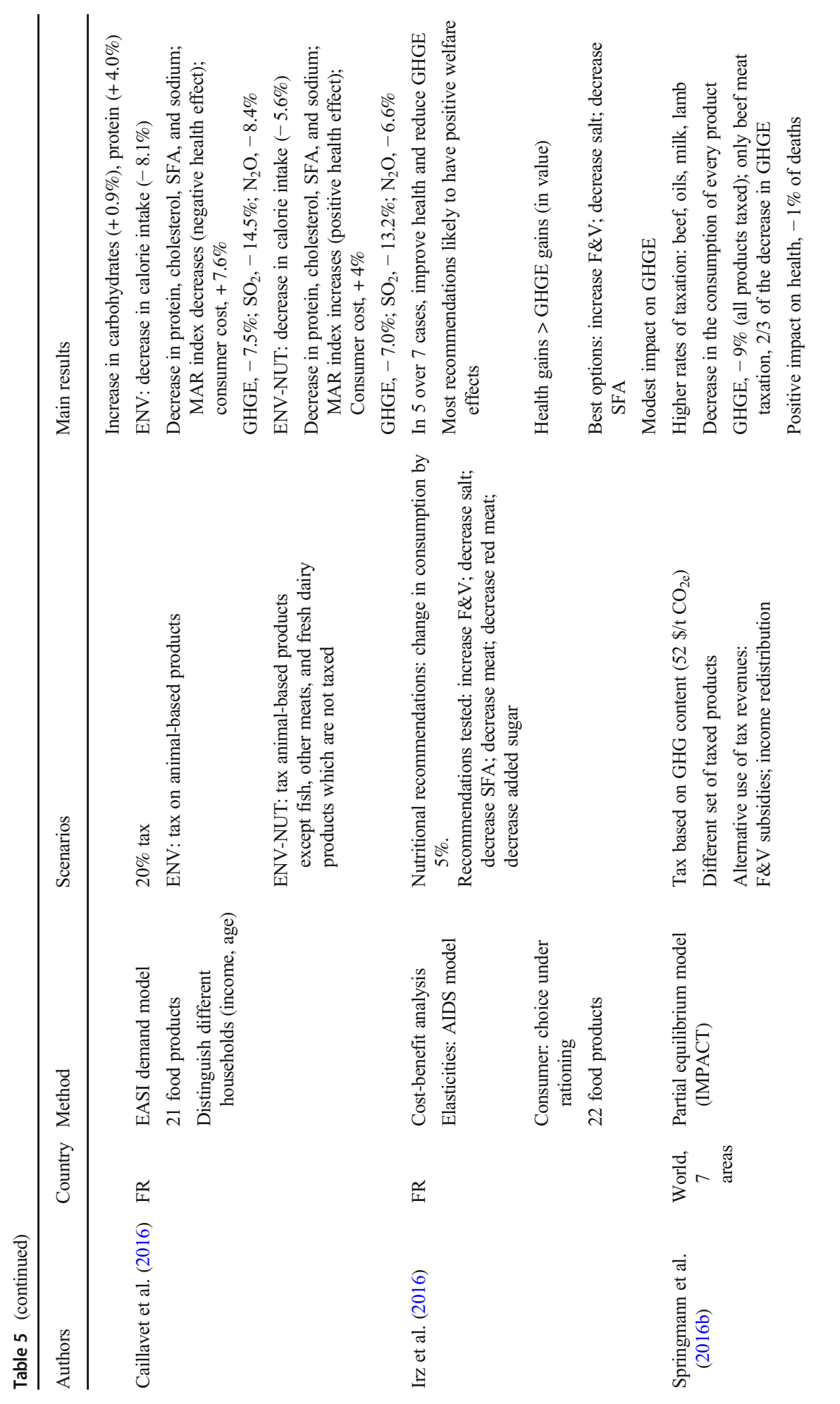




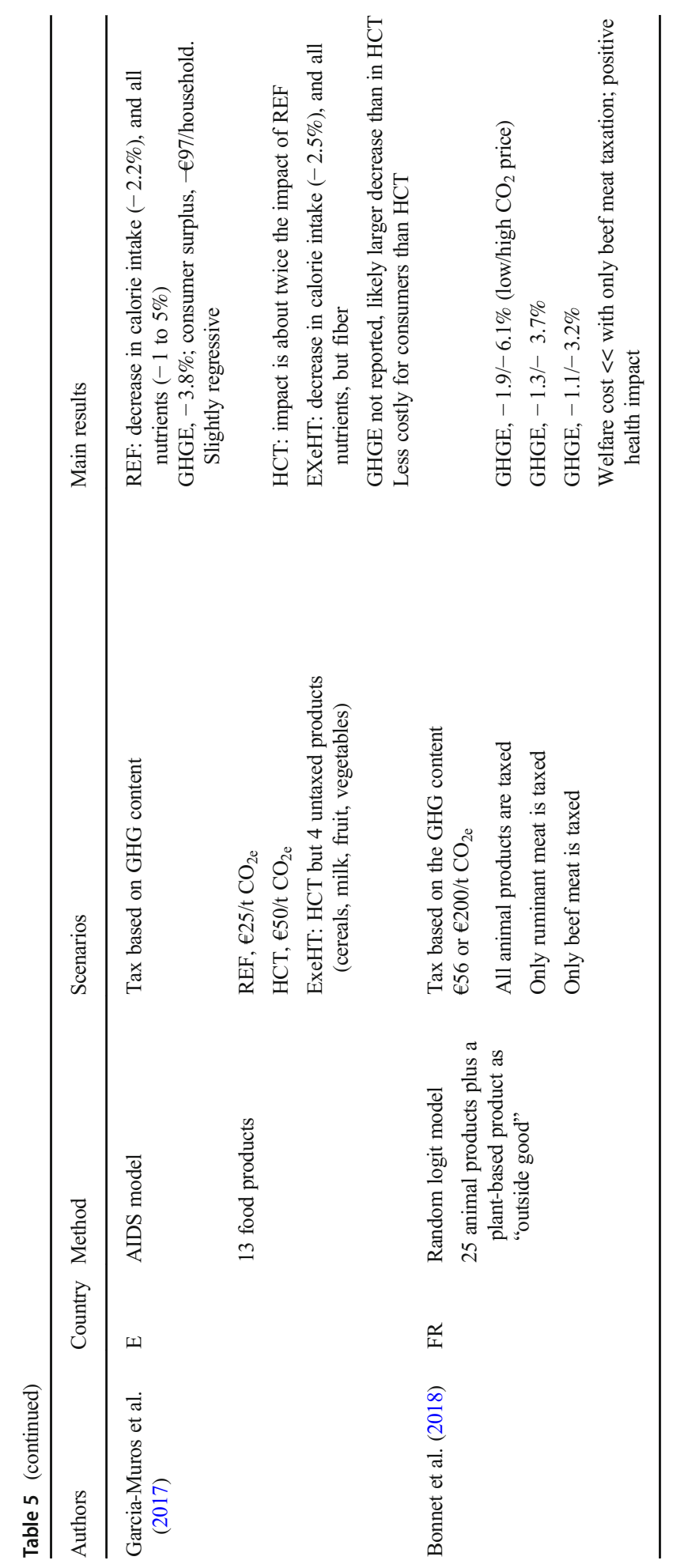


aggregation, these models account for substitution between food product categories, ignoring the intra-category substitutions. ${ }^{14}$

In what follows, we discuss in more detail the results of the simulated price policies. To do so, we distinguish between scenarios merely based on the taxation of a set of products and scenarios in which the revenues generated through taxes are used to subsidize another set of products. In the former case, there is no product experiencing a price reduction, whereas in the latter, some products undergo a decrease in price. This difference in the design of the scenarios has important consequences for the results. It is interesting to note that the policies analyzed in this section adopt a tax scheme with a primary focus on climate (except for the work on nutritional recommendations), while studies reviewed in the previous sections mainly have a nutritional motivation. This might be because GHGE are seen as an externality that requires public intervention, which justifies the advocacy of carbon taxation. Conversely, until now, nutritional policies have mainly targeted information on consumers and, when taxation is envisaged, it is mostly geared towards specific products, such as sugar-sweetened beverages.

\section{Scenarios of only taxation}

We first review the results of scenarios based on the taxation of all products or a subgroup of products (see Table 6). We report the results of six scenarios from five different papers. In most cases, the tax is based on the GHG content of the food products. ${ }^{15}$ In what follows, we report the main results assuming the tax is $€ 32 / \mathrm{t} \mathrm{CO}_{2}$ equivalent. ${ }^{16}$ Note also that a precise comparison of the results is difficult to achieve, as the impact of the tax, expressed as a percentage of the price for a given product, varies from one study to another, even when correcting for the value of $\mathrm{CO}_{2} .{ }^{17}$ The main conclusions are the following:

- Consumption of beef (and lamb) is the most impacted and decreases by a low $5 \%$ in Bonnet et al. (2018), in which substitutions between different beef products are allowed, and a high 20\% in Edjabou and Smed (2013). Consumption of beef products is the most impacted, as the tax is the highest for these products;

- Consumption of poultry products decreases less than the consumption of beef products, as a consequence of a lower tax rate, and also due to substitution effects with beef products. In one case (Edjabou and Smed 2013), poultry consumption increases while being taxed;

\footnotetext{
${ }^{14}$ Bonnet et al. (2018) focus on animal products and use a random logit model in which the "outside option" is an aggregate of plant-based products. Their analysis deals mainly with substitutions within the meat-product category.

15 The tax is expressed in $€ / t \mathrm{CO}_{2}$ equivalent. This is consistent with the GHGE data, which provides emissions in $\mathrm{CO}_{2}$ equivalent, that is considering the different greenhouse gases $\left(\mathrm{CO}_{2}, \mathrm{NH}_{4}, \mathrm{~N}_{2} \mathrm{O}, \ldots\right)$.

${ }^{16}$ To do so, we linearly extrapolate the results when the tax scenario is based on an explicit value of $\mathrm{CO}_{2}$. Then, the results from Edjabou and Smed (2013) are multiplied by 32/21.2 1.51; the results from Briggs et al. (2013), Bonnet et al. (2018), and Garcia-Muros et al. (2017) are multiplied by 1.01, 0.57, and 1.28, respectively. As Caillavet et al. (2016) do not base taxation on the $\mathrm{CO}_{2}$ content, we do not compare their quantitative results with the other studies.

${ }^{17}$ For example, in the case of beef meat with a $32 € / \mathrm{t} \mathrm{CO}$ tax, the impact varies from about $4 \%$ for some beef products considered in Bonnet et al. (2018) to about 16\% in Edjabou and Smed (2013).
} 
Table 6 Comparison of the impacts of environmental taxation on consumption, health, and GHG

\begin{tabular}{|c|c|c|c|c|c|c|}
\hline & $\begin{array}{l}\text { Briggs } \\
\text { et al. (2013) }\end{array}$ & $\begin{array}{l}\text { Edjabou } \\
\text { and Smed } \\
(2013)^{\mathrm{b}}\end{array}$ & $\begin{array}{l}\text { Abadie } \\
\text { et al. (2016) }\end{array}$ & $\begin{array}{l}\text { Caillavet } \\
\text { et al. } \\
(2016)\end{array}$ & $\begin{array}{l}\text { Garcia-Muros } \\
\text { et al. (2017) }\end{array}$ & $\begin{array}{l}\text { Bonnet } \\
\text { et al. } \\
(2018)\end{array}$ \\
\hline $\begin{array}{l}\text { Carbon tax } \\
\qquad\left(/ \mathrm{CO}_{2}\right)\end{array}$ & $£ 27.2=€ 31.6$ & $\$ 29=€ 21.2$ & & & $€ 25$ & $€ 56$ \\
\hline Taxation rule & $\begin{array}{c}\text { Pdts GHGE } \\
>4.1 \mathrm{~kg} \\
\mathrm{CO}_{2} / \mathrm{kg}\end{array}$ & All & Endogenous & $\begin{array}{c}\text { Animal } \\
\text { prod- } \\
\text { ucts }\end{array}$ & All & $\mathrm{All}^{\mathrm{d}}$ \\
\hline \multicolumn{7}{|l|}{ Tax level } \\
\hline Beef & $2.0(€ / \mathrm{kg})$ & $11.1 \%$ & $9 \%$ & $20 \%$ & $6.0 \%$ & $\begin{array}{l}6 \text { to } \\
12 \%\end{array}$ \\
\hline Pork & $0.1(€ / \mathrm{kg})$ & $2.0 \%$ & $-5 \%$ & $20 \%$ & $4.2 \%$ & 2 to $5 \%$ \\
\hline Poultry & $0.05(€ / \mathrm{kg})$ & $2.5 \%$ & $-15 \%$ & $20 \%$ & $2.2 \%$ & 3 to $9 \%$ \\
\hline Cheese & 0 & $4.9 \%$ & $0 \%$ & $20 \%$ & $4.4 \%$ & $7 \%$ \\
\hline Sugar & 0 & $1.4 \%$ & $40 \%$ & 0 & $2.1 \%$ & $\mathrm{nc}$ \\
\hline $\mathrm{F} \& \mathrm{~V}$ & 0 & 1.0 to $2.7 \%$ & $\begin{array}{c}\mathrm{F},-7 \% ; \mathrm{V} \\
-10 \%\end{array}$ & 0 & 2.1 to $4.4 \%$ & $\mathrm{nc}$ \\
\hline \multicolumn{7}{|l|}{$\Delta$ consumption } \\
\hline Beef & $-14.2 \%$ & $-13 \%$ & $-25 \%$ & & $-7.5 \%$ & $-8.3 \%$ \\
\hline Pork & $-1.2 \%$ & $-2 \%$ & $+6 \%$ & & $-2.5 \%$ & $-0.5 \%$ \\
\hline Poultry & $-0.2 \%$ & $+1 \%$ & $+12 \%$ & & $-3 \%$ & $-3.8 \%$ \\
\hline Cheese & $-0.2 \%$ & $-3 \%$ & $-10 \%$ & & $-5 \%$ & $-1.8 \%$ \\
\hline Sugar & $-0.2 \%$ & $+3 \%$ & $+6 \%$ & & $-1 \%$ & $\mathrm{nc}$ \\
\hline $\mathrm{F} \& \mathrm{~V}$ & $\begin{array}{c}\mathrm{F},+0.2 \% ; \mathrm{V} \\
\quad-0.4 \%\end{array}$ & $\mathrm{~F},+4 \% ; \mathrm{V}, 0 \%$ & $0 \%$ & & $-4 \%$ & $\mathrm{nc}$ \\
\hline $\begin{array}{l}\text { Nber pdts } \Delta \\
\quad \text { cons }>0\end{array}$ & $3($ of 29$)$ & $10($ of 23$)$ & 2 (of 30) & 0 (of 13) & & \\
\hline \multicolumn{7}{|l|}{$\Delta$ nutrients } \\
\hline Calories & $-1.4 \%$ & $-2.0 \%$ & Isocaloric & $-8.1 \%$ & $-2.2 \%$ & $-0.7 \%$ \\
\hline $\begin{array}{l}\text { SFA } \\
\text { Carbohy- } \\
\text { drates }\end{array}$ & $-2.8 \%$ & $-4.0 \%$ & $\begin{array}{l}-10.4 \% \\
-0.7 \%\end{array}$ & $\begin{array}{l}-15.7 \% \\
-3.0 \%\end{array}$ & $\begin{array}{l}-3.0 \% \\
-1.2 \%\end{array}$ & $-1.6 \%$ \\
\hline Sugar & $-0.4 \%$ & $0.3 \%$ & $-1.2 \%$ & $-3.2 \%$ & $-2.7 \%$ & \\
\hline \multicolumn{7}{|c|}{ Aggregate impacts } \\
\hline $\begin{array}{l}\Delta \text { GHGE } \\
\text { Diet quality } \\
\text { index }\end{array}$ & $-7.5 \%$ & $-7.9 \%$ & $-5 \%$ c & $\begin{array}{l}-7.5 \% \\
-0.3\end{array}$ & $-3.8 \%$ & $-1.9 \%$ \\
\hline DA & $7770(3.4 \%)^{\mathrm{a}}$ & & & & & \\
\hline $\begin{array}{l}\Delta \text { consumer } \\
\text { surplus }\end{array}$ & & $€ 29 /$ pers./year & & & $€ 97 / \mathrm{hh} /$ year & $-0.9 \%$ \\
\hline
\end{tabular}

SFA, saturated fatty acid; pers., person; $h$, household; $D A$, deaths avoided

a Based on a total number of deaths from the modeled diseases of 226,743 in 2008, cf. Scarborough et al. (2012)

${ }^{\mathrm{b}}$ We only report scenario S1A, as detailed results for scenario S1B are not provided

c The reduction of GHGE is imposed. The tax scheme is determined endogenously to reach the imposed reduction in GHGE

d This paper considers 21 meat products, seven other animal products, a dairy product aggregate, and a plantbased aggregate substitute 
- Consumption of the majority of products decreases as a reaction to the taxation scheme. As the consumption of most products decreases, the calorie intake decreases in the range of -1.5 to $-3 \%$ for models that are based on the whole diet;

- Consumption of SFA and carbohydrates decreases, whereas the consumption of sugar might increase. The aggregate health impact might be positive as the number of DA is positive (although evaluated in only one study). However, the diet quality index might decrease as shown in the "ENV" scenario in Caillavet et al. (2016);

- GHGE are reduced by 5 to $12 \%$ for models that are based on the whole diet;

- A significant part of this reduction is linked to the reduction in beef (lamb) consumption. Another part is linked to the overall decrease in calorie consumption;

- Consumer surplus, ignoring health or climate impacts, decreases by $€ 45$ to 50 per person per year.

An important conclusion that emerges is that the reduction in GHGE through a tax based on the GHG content of products (assuming a value of $€ 32 / t \mathrm{CO}_{2}$ ) is smaller than that reported in the previous sections of this paper. This reduction is mainly the consequence of a decrease in the consumption of beef (and lamb) products, as well as a "scale" effect following a reduction in the calorie intake. For example, Bonnet et al. (2018) find a very small decrease in GHGE, as well as low changes in calorie intake. Caillavet et al. (2016) find a reduction in GHGE that is as large as the reduction in the calorie intake. Net of the scale effect, the reduction in GHGE is between 2 and $9 \%$ for models based on the whole diet. With respect to the health dimension, only one study evaluates the aggregate health impact, which is positive. However, a significant part of the positive health effect is linked to a reduction in calorie intake. Contrarily, Caillavet et al. (2016) find a negative impact on the diet quality. In sum, the results on the health impact of GHGE taxation are mixed.

Finally, it is important to note that, for these scenarios, the consumption of most products decreases, which mainly depends on the fact that the models used only consider food demand, rather than a complete demand system also integrating demand for nonfood products. Specifically, a reallocation of the consumer budget between food products and non-food products is not taken into account. ${ }^{18}$ In other words, it is likely that these models over-estimate the decrease in consumption of animal products induced by the tax policy. As a consequence, they certainly over-estimate the decrease in GHGE driven by taxation.

\section{Scenarios of revenue-neutral price policies}

In a small number of papers, the simulated scenarios include revenue-neutral schemes of taxation. The revenues from the carbon tax allow the subsidization of some products or decreasing the Value-Added Tax (VAT) for all products (Table 7). Briggs et al. (2013) define a revenue-neutral scenario in which products with GHGE above a given

\footnotetext{
${ }^{18}$ The impact of ignoring this effect becomes particularly visible when exploring high levels of tax. For example, Edjabou and Smed (2013) simulate two levels of carbon tax: the one reported here, and another based on a carbon price of $62 € / \mathrm{t} \mathrm{CO}_{2}$. In the latter case (scenario 1B), they report a decrease in calorie consumption as high as $5.3 \%$, which is extremely large.
} 
Table 7 Comparison of the impacts on consumption, health and GHGE of revenue-neutral price policies

\begin{tabular}{|c|c|c|c|}
\hline & \multirow[t]{2}{*}{ Briggs et al. (2013) } & \multicolumn{2}{|l|}{ Edjabou and Smed (2013) } \\
\hline & & S-2A & $\mathrm{S}-2 \mathrm{~B}$ \\
\hline Carbon tax $\left(/ \mathrm{t} \mathrm{CO} \mathrm{CO}_{2}\right)$ & $£ 27.2=€ 31.6$ & $\$ 29=€ 21.2$ & $\$ 85=€ 62$ \\
\hline Taxation rule & $\begin{array}{l}\text { Tax on products } \\
\text { GHGE, }>4.1 \mathrm{~kg} \mathrm{CO}_{2} / \mathrm{kg} \\
\text { Subsidies for products } \\
\text { GHGE, }<4.1 \mathrm{~kg} \mathrm{CO}_{2} / \mathrm{kg}\end{array}$ & $\begin{array}{l}\text { All products: carbon tax } \\
\text { and decrease in } \mathrm{VAT}^{\mathrm{a}}\end{array}$ & $\begin{array}{l}\text { All products: carbon tax } \\
\text { and decrease in } \mathrm{VAT}^{\mathrm{a}}\end{array}$ \\
\hline \multicolumn{4}{|l|}{ Tax level } \\
\hline Beef & $2.0(€ / \mathrm{kg})$ & $8.5 \%$ & $25.3 \%$ \\
\hline Pork & $0.1(€ / \mathrm{kg})$ & $-0.6 \%$ & $-1.4 \%$ \\
\hline Poultry & $0.05(€ / \mathrm{kg})$ & $-0.2 \%$ & $0.0 \%$ \\
\hline Cheese & $-0.07(€ / \mathrm{kg})$ & $2.3 \%$ & $7.1 \%$ \\
\hline Sugar & $-0.13(€ / \mathrm{kg})$ & $-1.2 \%$ & $-2.9 \%$ \\
\hline $\mathrm{F} \& \mathrm{~V}$ & -0.08 to $-0.1(€ / \mathrm{kg})$ & $\mathrm{F},-1.6 \% ; \mathrm{V}, 0.1 \%$ & $\mathrm{~F},-4.3 \% ; \mathrm{V}, 0.9 \%$ \\
\hline \multicolumn{4}{|l|}{$\Delta$ consumption } \\
\hline Beef & $-13.7 \%$ & & $-32 \%$ \\
\hline Pork & $-0.7 \%$ & & $-6 \%$ \\
\hline Poultry & $-0.3 \%$ & & $+2 \%$ \\
\hline Cheese & $+0.9 \%$ & & $-9 \%$ \\
\hline Sugar & $+5.0 \%$ & & $+8 \%$ \\
\hline $\mathrm{F} \& \mathrm{~V}$ & $\mathrm{~F},+3.5 \% ; \mathrm{V},+2.4 \%$ & & $\mathrm{~F},+9 \% ; \mathrm{V},-1.5 \%$ \\
\hline Nber pdts $\Delta$ cons $>0$ & $19($ of 29$)$ & & $13($ of 23$)$ \\
\hline \multicolumn{4}{|l|}{$\Delta$ nutrients } \\
\hline Calories & $+1.0 \%$ & $+2.2 \%$ & $+6.1 \%$ \\
\hline SFA & $-1.2 \%$ & $-0.1 \%$ & $0.0 \%$ \\
\hline \multicolumn{4}{|l|}{ Carbohydrates } \\
\hline Sugar & $+4.2 \%$ & $+3.1 \%$ & $+8.9 \%$ \\
\hline \multicolumn{4}{|l|}{ Aggregate impacts } \\
\hline$\Delta$ GHGE & $-6.1 \%$ & $-3.4 \%$ & $-8.8 \%$ \\
\hline $\mathrm{DA}$ & $-2685(-1.2 \%)$ & & \\
\hline$\Delta$ consumer surplus & & $+€ 1 /$ pers./year & $€ 2 /$ pers./year \\
\hline
\end{tabular}

${ }^{a}$ All products are taxed in function of their GHG content, and benefit from a reduction in the VAT

threshold are taxed and products with GHGE below the threshold are subsidized. Edjabou and Smed (2013) use a different rule: all products are taxed proportionally to their GHG content and all products benefit from the same abatement in VAT. In what follows, we report the main results assuming the tax is $€ 32 / \mathrm{CO}_{2}{ }^{19}$ :

\footnotetext{
${ }^{19}$ As in the previous section, we linearly extrapolate the results to "estimate" the impact of considering such a carbon price.
} 
- As a consequence of supporting the highest tax, consumption of beef (and lamb) is the most impacted item;

- Consumption of some products decreases (meat products in particular), whereas consumption of other products increases (fruit, as well as some energy-dense products);

- Calorie consumption increases by 1 to $3 \%$. This is linked to the increased consumption of energy-dense products benefiting from net subsidies that counterbalances the decreased consumption of meat products;

- Consumption of SFA might decrease by a small amount whereas the consumption of sugar, as a nutrient, increases by about $4 \%$. The impact on health is likely to be negative;

- Due to substitutions between food products, GHGE are reduced by 4.5 to 6\%;

- Consumer surplus, ignoring health or climate impacts, is almost unaffected.

There are three subsets of results that derive from these analyzes. First, the results suggest that the reduction in GHGE is smaller than that reported in the case of taxation only; about $5 \%$ for a $€ 32 / \mathrm{t} \mathrm{CO}_{2}$ carbon tax. As a consequence, unless taxation is based on higher values of $\mathrm{CO}_{2}$, the reduction in GHGE through a change in consumption is rather limited, well below the objective of cutting GHGE from agriculture by $20 \%$. It also appears that taxing products with a high GHG content and subsidizing those with a low GHG content is likely to have negative impacts on health, as a consequence of increased calorie consumption and an increased consumption of sugars. This is due to the fact that the policy assigns subsidies to energy-dense products, such as soft drinks and sugary products, thus leading to adverse health effects. This is a very important conclusion that sheds light on the non-existence of an automatic convergence between a health objective and a climate attenuation objective. Finally, the impact on consumer surplus is very small, which means that the revenue-neutral policies improving both the health and the climate dimensions are likely to be highly costeffective and welfare-improving.

\section{Comparison of health and climate benefits}

As discussed previously, changes in diet impact both health and the climate. The objective of this section is to compare, in monetary terms, the relative importance of these two effects. To do so, among the different studies reported in the previous sections, we retain those that provide both an estimate of the health impact (the number of DA or the number of disability-adjusted life years (DALY)) and an estimate of the impact on GHGE. Although, as already discussed in the previous sections, these studies rely on a different array of methodologies, they provide information on health and GHGE for a sound scenario of consumption change. To assign a monetary value to these impacts, we avail ourselves of conventional values that are used extensively in cost-benefit analysis. For the health impact, we use the monetary value of a statistical life (VSL), defined as the effort, in terms of resource usage, that society is willing to make in order to reduce the risk of death. 
The VSL is commonly adopted in economic and policy analysis. ${ }^{20}$ For instance, in the transportation sector, the VSL reported by Anderson and Treich (2011) ranges from US\$1.8 million (2005) for New Zealand to US\$3.3 million (2005) for the USA, with the three represented EU countries displaying values in the order of US\$2 million (2005). Valuing the benefit of reduced externalities also proves difficult on the environmental side. In the case of carbon emissions, we rely on the meta-analysis of the social cost of carbon developed by Tol (2012). The author, after fitting a distribution of 232 published estimates, derives a median of $€ 32 / \mathrm{t}$, which we adopt in this analysis. We also present results in the case of a higher value of the social cost of carbon $(€ 56 / t)$, following some recent policy debates that suggest higher values for the cost of carbon in order to provide higher incentives for GHGE reduction.

In Table 8, we report the health impact (in DA or DALY), the avoided GHGE for 15 scenarios from five different studies (four studies in the UK and one study in France). In most cases (12 cases over 15), the scenarios have a positive impact on both dimensions. Given the VSL and the social cost of $\mathrm{CO}_{2}$, we compute the health and climate benefits as well as the ratio of climate benefits and health benefits. In the majority of cases, it appears that the climate impact (as measured by the benefit of avoiding GHGE only) is generally small as compared with the health impact, as the ratio of climate benefits over health benefits lies between 0.01 and 0.21 with a $\mathrm{CO}_{2}$ value of $€ 32 / \mathrm{t}^{21}$ As a consequence, the climate policies targeting food products should be designed in such a way that their impact on health is not negative. Otherwise, it is likely that the policy would result in a negative welfare impact.

\section{Conclusion: research needs and policy perspectives}

There are broadly three groups of studies addressing the impact of modifying diets on health and the climate. ${ }^{22}$ It is crucial to make this distinction, as the results must be interpreted in line with the main assumptions that are inherent to each of the methodologies dealt with in this survey.

Studies based on ad hoc changes suggest a convergence between health and climate objectives. However, since the substitutions between food products are chosen by the modeler and not by the consumers, these results should be interpreted with great caution. In our opinion, the results offer some general directions that could help in the design of policies. They deliver both a positive message (that is, the plausible convergence between health and climate objectives), and a less optimistic message (related to the fact that large decreases in GHGE from diet changes are unlikely).

Studies based on optimized diets confirm the possibility of designing diets that are both healthy and climate friendly, and suggest that reaching substantial reductions in GHGE, while satisfying nutritional recommendations, is not impossible. However, there is no consensus regarding the impact of adopting nutritional recommendations

\footnotetext{
${ }^{20}$ For a review, see Treich (2015).

${ }^{21}$ Springmann et al. (2016a) found similar results when analyzing the potential impact of diet changes at the world level.

${ }^{22}$ A fourth group of studies, which is not reviewed in this survey, focuses on the analysis of the heterogeneity of self-selected diets (see Perignon et al. 2017).
} 


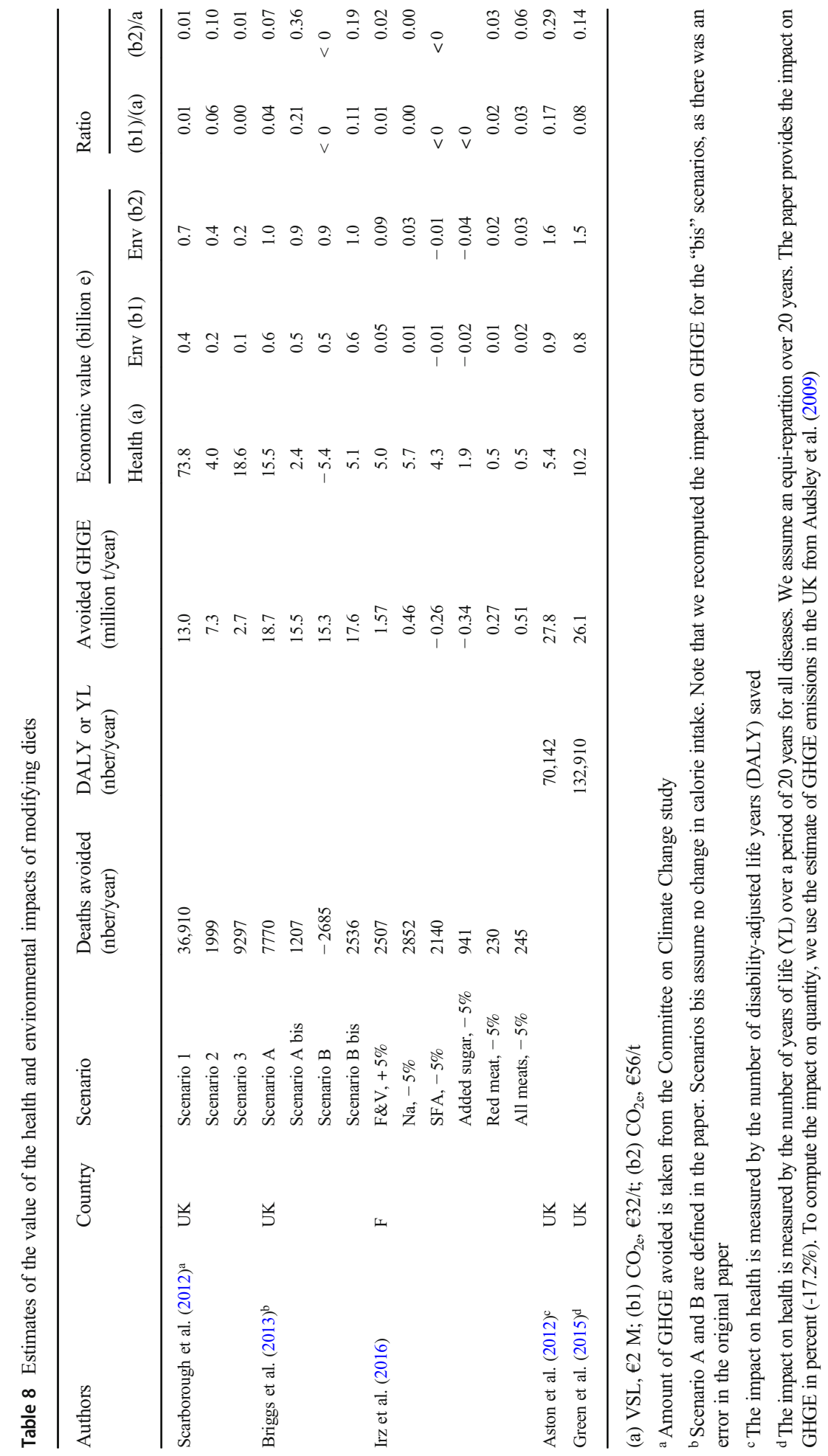


on GHGE. ${ }^{23}$ In the former case, the model integrates nutritional and GHGE constraints, whereas in the latter case, GHGE are computed as the consequence of nutritional choices and are not a constraint in the choice of food products. Results also suggest that to achieve significant reductions in GHGE with nutritionally adequate diets, significant changes in diet composition are required. Changes in diet involve both substitutions between food product categories and within food product categories. This is of critical importance, as, from a consumer's perspective, it is certainly easier to substitute between products within a product category rather than between categories. A central issue of this class of models is related to the methodology itself, and more precisely to the definition of the objective function and to the addition of ad hoc non-nutritional constraints. These constraints are frequently referred to as "palatability" or "acceptability" constraints, although their role is not detailed (for example, it is difficult to know which of these constraints are binding at the optimum and, as a consequence, impact the results). Thus, the main limitation of this class of models lies in the fact that consumer preferences are not properly taken into account. In other words, this class of models guides us as to which substitutions to prioritize but is silent about the policies that could provide consumers with the incentives to modify their diets in the "desired" direction.

Economic studies provide a less optimistic view. First, the order of magnitude of the decrease in GHGE is much lower (frequently lower than 10\%), unless high levels of taxation are put into force. Second, a carbon tax policy, which consists of taxing products with a high GHG content and subsidizing those with a low GHG content, is likely to have negative health impacts. This is mainly due to the fact that such a policy subsidizes energy-dense products that have a negative impact on health. As shown by Springmann et al. (2016b), in order to achieve convergence between the two objectives in a revenue-neutral policy, one has to tax products with a high GHG content (ruminant meat in particular) and invest the revenues to subsidize healthy products, such as fruit and vegetables. In this case, it is more likely that consumers will choose diets that are healthier and more climate friendly. The results of the different studies also show that, when there is a convergence between the two objectives, the health effect is higher in monetary terms, sometimes in large proportions, as compared with the environmental impact. This is an important consideration for policy design. In particular, it means that the design of environmental policies should take into account the induced health impact of policies. More generally, because the substitutions/complementarities between food products are complex, it is not granted that a policy targeting one dimension will generate positive effects on the other dimensions. Notwithstanding, given the multiple possibilities of substitution and complementarity between products, it is possible to design a policy that does improve both dimensions.

There are still a number of aspects that need to be better analyzed. First, since the economic models consider a small number of product categories, the economic analysis mostly overlooks the problem of substituting within a product category. This represents a limit as, from the consumer's point of view, substitutions between categories are

\footnotetext{
${ }^{23}$ As reported in Table 4, a recent study suggests that complying with nutritional recommendations might lead to higher GHGE, whereas other studies state the contrary. This conclusion is consistent with analyses developed in the case of self-selected diets. Thus, Vieux et al. (2013) show that "high-nutritional-quality diets have significantly higher GHGE than low-nutritional-quality diets."
} 
likely to be more difficult to realize than substitutions within product categories. This remains a difficulty that, at present, cannot be assessed in the models developed so far, unless they focus on a specific group of products.

Second, one should keep in mind that, in most cases, a significant proportion of the health benefit derives from the change in calorie consumption. ${ }^{24}$ This change is a fundamental factor that needs to be better understood. Simulations of taxation policies (non-neutral schemes of taxation) generally lead to a decrease in calorie consumption; a result which might be linked to poor accounting of budget reallocation between food and non-food products. This issue is a priori much less important in the revenue-neutral simulations, in which there is a rebalancing of consumption between products. However, anticipating calorie changes induced by a change in the diet remains key, as it affects the relative importance of the health and climate impacts.

Third, the GHG content of each product is derived from the life cycle analysis (LCA) method, which intends to take into account the emissions generated throughout the entire cycle of production. However, there is a large variability in the values that are used in the reported studies. This is clearly a limitation in the empirical results of all the reported studies. From a more methodological viewpoint, an additional drawback consists of the lack of integrating some key consequences of modifying the level of production of an "activity.", In our case, a major difficulty relates to the change in land use. As exemplified by the case of biofuels, taking into account (or not) changes in land use is not neutral (Searchinger et al. 2008). ${ }^{26}$ In the case of changes in diet, integrating land use changes in the analysis might improve the environmental impact. For example, Westhoek et al. (2014) evaluate the impact of diet changes on GHGE, taking into account (or not) the change in land use. In their case, any land removed from production is converted into perennial bio-energy crops, which is a favorable option for the land that is made available. However, their results clearly show that, when changes in land use are taken into account, the reduction in GHGE associated with a change in diet is larger and, sometimes, in significant proportions. More generally, since, in most cases, the recommended diets are more plant based, it is likely that the demand for land will decrease overall. For example, Aleksandrowicz et al. (2016) demonstrate that switching from current diets to healthy guidelines leads to lower land usage (median value, $-20 \%$ ). As a consequence, it is possible that integrating land use changes in the analysis will improve the impact on the climate. This is an important aspect that needs to be better assessed in future studies.

Fourth, a frequently ignored issue is the so-called rebound effect. If consumers modify their diets for any reason, their food expenditure will be affected. As a consequence, their other expenditures will also be affected, and the GHGE associated

\footnotetext{
$\overline{{ }^{24}}$ The study by Briggs et al. (2013) provides some quantitative elements. In Scenario A (see 8), the number of DA is 7770 but is reduced to 1207 when adjusting for the change in calories. That is, $85 \%$ of the number of $\mathrm{DA}$ is due to the change in calories, whereas the remaining number is due to the change in the composition of the diet. Moreover, in Scenario B, which leads to an increase in calorie consumption, the number of DA is actually negative. When corrected for the change in calories (Scenario B "bis"), the impact on health is positive. Irz et al. (2015) also show that the health impact is mostly due to a change in calorie intake.

${ }^{25}$ The development of the so-called consequential LCA is a way to deal with this type of problem (Zamagni et al. 2012).

${ }^{26}$ In the case of biofuels, taking into account land use changes leads us to estimate much lower gains in GHGE from biofuel production. This is because biofuel production induces an increase in the quantity of land used for agriculture, which puts into production areas that were rich in carbon.
} 
with the non-food expenditures will also vary. Tukker et al. (2011) integrate this effect and find that it has a limited impact on the results. However, there is room for a better integration of the rebound effect in the economic evaluation of policies.

Until now, in the EU, most of the policies aiming at modifying diet choices are nutritional policies; that is, policies that aim to improve the nutritional quality of diets. This is the case, for example, of the labeling policy which defines mandatory nutritional information. In addition, some countries have implemented voluntary front-of-the-pack nutritional labeling (e.g., the traffic light label in the UK, Nutriscore in France). The impact of such initiatives is likely to be limited, in particular for low-income consumers (Drichoutis et al. 2012). It is interesting to note that Tesco, a UK retailer, has experimented with carbon footprint labeling. This initiative was not pursued as the label had little or no effect on purchases (Hornibrook et al. 2015).

Nutritional recommendations have been published in several EU countries and generally provide a large number of recommendations. The most well-known is the "5-a-day" recommendation, encouraging fruit and vegetable consumption. Ex postevaluation of such a campaign tends to show that the associated nutritional recommendations are having a small and positive (about half a portion per day) impact on consumption (Capacci and Mazzochi 2011). Interestingly, Castiglione and Mazzochi (2019) showed that, in the UK, the increase in fruit and vegetable consumption was also accompanied by a reduction in meat consumption, suggesting that the likely impact on GHGE of the campaign is heading in the right direction. Irz et al. (2016) concluded that, even if these campaigns have only a small impact on consumption, they should be nonetheless encouraged as they are likely to be welfare improving, given their positive impact on both health and the environment.

Some countries have been implementing tax policies on sugar-sweetened beverages. One of the objectives of such a policy is to combat the rise in obesity. In the past, Denmark implemented a tax on fat products, targeting animal products (Jensen and Smed 2013), which was developed for health reasons, more than for environmental reasons. This is to say that, as far as we know, until now, in the EU there are no food policies that are motivated by an environmental dimension. In some cases, nutritional recommendations provide an upper bound to meat consumption, but this remains a rather weak signal. More ambitious sets of coordinated policies, including information, education, nudges, and price policies, have to be implemented in order to favor the adoption of more plant-based diets by consumers.

Overall, this survey points out that there are options to design and provide consumers with the incentives to adopt healthier and more climate-friendly diets. However, since food consumption habits change slowly, it is likely that the associated reduction in GHGE will be small, compared with the EU target of reducing GHGE. This emphasizes the urgent need to improve the performance of production systems in a way that limits GHGE. In other words, one cannot rely solely on the change in consumption to tackle the climate change challenge. Similarly, it is interesting to note that, from a health point of view, the content of food products, and how to ameliorate this through a reformulation of policies, is also crucial for an improvement in the healthiness of diets.

Acknowledgments We thank Dominique Bureau, Hervé Guyomard, Nicolas Treich, and two anonymous referees for their helpful comments on an earlier version of this paper. 
Funding information We conducted this research as part of the project DIETPLUS ANR17-CE21-0003 funded by the French National Research Agency (ANR). In addition, financial support from the ERANETSUSFOOD call (Project SUSDIET: Daniel and Nina Carasso Foundation) and INRA metaprogramm DIDIT is also gratefully acknowledged. Finally, we also acknowledge funding from the French National Research Agency (ANR) under the Investments for the Future (Investissements d'Avenir) program, grant ANR-17EURE-0010.

\section{Compliance with ethical standards}

Conflict of interest The authors declare that they have no conflict of interest.

Open Access This article is licensed under a Creative Commons Attribution 4.0 International License, which permits use, sharing, adaptation, distribution and reproduction in any medium or format, as long as you give appropriate credit to the original author(s) and the source, provide a link to the Creative Commons licence, and indicate if changes were made. The images or other third party material in this article are included in the article's Creative Commons licence, unless indicated otherwise in a credit line to the material. If material is not included in the article's Creative Commons licence and your intended use is not permitted by statutory regulation or exceeds the permitted use, you will need to obtain permission directly from the copyright holder. To view a copy of this licence, visit http://creativecommons.org/licenses/by/4.0/.

\section{References}

Abadie, L., Galarraga, I., Milford, A., \& Gustavsen, G. (2016). Using food taxes and subsidies to achieve emission reduction targets in Norway. Journal of Cleaner Production, 134, Part A, 280-297. Special volume: Transitions to sustainable consumption and production in cities.

Aleksandrowicz, L., Green, R., Joy, E. J. M., Smith, P., \& Haines, A. (2016). The impacts of dietary change on greenhouse gas emissions, land use, water use, and health: A systematic review. PLoS One, 11(11), 116.

Anderson, H., \& Treich, N. (2011). The value of a statistical life. In Handbook of transport economics. Cheltenham: Edward Elgar Publishing.

Aston, L., Smith, J., \& Powles, J. (2012). Impact of a reduced red and processed meat dietary pattern on disease risks and greenhouse gas emissions in the UK: A modelling study. British Medical Journal, 2, e001072.

Audsley, E., Brander, M., Chatterton, J., Murphy-Bokern, D., Webster, C., \& Williams, A. (2009). How low can we go? an assessment of greenhouse gas emissions from the UK food system and the scope to reduce them by 2050 . Technical report, FCRN-WWF-UK.

Auestad, N., \& Fulgoni, V. L. (2015). What current literature tells us about sustainable diets: Emerging research linking dietary patterns, environmental sustainability, and economics. Advances in Nutrition, 6 , 19-36.

Bonnet, C., Bouamra-Mechemache, Z., \& Corre, T. (2018). An environmental tax towards more sustainable food: Empirical evidence of the consumption of animal products in France. Ecological Economics, 147, 48-61.

Briggs, A., Kehlbacher, A., Tiffin, R., Garnett, T., Rayner, M., \& Scarborough, P. (2013). Assessing the impact on chronic disease of incorporating the societal cost of greenhouse gases into the price of food: An econometric and comparative risk assessment modelling study. BMJ Open, 3, e003543.

Caillavet, F., Fadhuile, A., \& Nichèle, V. (2016). Taxing animal-based foods for sustainability: Environmental, nutritional and social perspectives in France. European Review of Agricultural Economics, 43(4), 537-560.

Capacci, S., \& Mazzocchi, M. (2011). Five-a-day, a price to pay: an evaluation of the UK program impact accounting for market forces. Journal of Health Economics, 30(1), 87-98.

Castiglione, C., \& Mazzochi, M. (2019). Ten years of five-a-day policy in the UK: Nutritional outcomes and environmental effects. Ecological Economics, 157, 185-194.

Drichoutis, A., Nayga, R., \& Lazaridis, P. (2012). Nutritional labeling. The Oxford handbook of the economics of food consumption and policy. Oxford University Press. 
Edjabou, L. D., \& Smed, S. (2013). The effect of using consumption taxes on foods to promote climate friendly diets the case of Denmark. Food Policy, 39, 84-96.

Estaquio, C. (2011). Scores nutritionnels: méthodes, aspects socio-économiques et association avec l'état nutritionnel et la morbidité dans la cohorte SU.VI.MAX. PhD thesis, CNAM.

Garcia-Muros, X., Markandya, A., Romero-Jordan, D., \& Gonzalez-Eguino, M. (2017). The distributional effects of carbon-based food taxes. Journal of Cleaner Production, 140(Part 2), 996-1006.

Garnett, T. (2011). Where are the best opportunities for reducing greenhouse gas emissions in the food system (including the food chain)? Food Policy, 36(Supplement 1), S23-S32.

Green, R., Milner, J., Dangour, A. D., Haines, A., Chalabi, Z., Markandya, A., Spadaro, J., \& Wilkinson, P. (2015). The potential to reduce greenhouse gas emissions in the UK through healthy and realistic dietary change. Climatic Change, 129(1), 253-265.

Hallstrom, E., Carlsson-Kanyama, A., \& Borrjesson, P. (2015). Environmental impact of dietary change: A systematic review. Journal of Cleaner Production, 91, 1-11.

Hoolohan, C., Berners-Lee, M., McKinstry-West, J., \& Hewitt, C. (2013). Mitigating the greenhouse gas emissions embodied in food through realistic consumer choices. Energy Policy, 63, 1065-1074.

Horgan, G. W., Perrin, A., Whybrow, S., \& Macdiarmid, J. I. (2016). Achieving dietary recommendations and reducing greenhouse gas emissions: Modelling diets to minimise the change from current intakes. International Journal of Behavioral Nutrition and Physical Activity, 13(1), 46.

Hornibrook, S., May, C., \& Fearne, A. (2015). Sustainable development and the consumer: Exploring the role of carbon labelling in retail supply chains. Business Strategy and the Environment, 24(4), 266-276.

IPCC (2013). Climate change 2013: The physical science basis. Contribution of Working Group I to the Fifth Assessment Report of the Intergovernmental Panel on Climate Change. In: Stocker, T.F., D. Qin, G.-K. Plattner, M. Tignor, S.K. Allen, J. Boschung, A. Nauels, Y. Xia, V. Bex \& P.M. Midgley (eds.) Cambridge University Press, Cambridge, United Kingdom, 1535 pp.

Irz, X., Leroy, P., Réquillart, V., \& Soler, L.-G. (2015). Economic assessment of nutritional recommendations. Journal of Health Economics, 39, 188-210.

Irz, X., Leroy, P., Réquillart, V., \& Soler, L.-G. (2016). Welfare and sustainability effects of dietary recommendations. Ecological Economics, 130, 139-155.

Jensen, J. D., \& Smed, S. (2013). The Danish tax on saturated fat: Short run effects on consumption, substitution patterns and consumer prices of fats. Food Policy, 42, 18-31.

Joyce, A., Hallett, J., Hannelly, T., \& Carey, G. (2014). The impact of nutritional choices on global warming and policy implications: Examining the link between dietary choices and greenhouse gas emissions. Energy and Emission Control Technologies, 2, 33-43.

Macdiarmid, J. I., Kyle, J., Horgan, G. W., Loe, J., Fyfe, C., Johnstone, A., \& McNeill, G. (2012). Sustainable diets for the future: Can we contribute to reducing greenhouse gas emissions by eating a healthy diet? American Journal of Clinical Nutrition, 96, 632-639.

Meier, T., \& Christen, O. (2013). Environmental impacts of dietary recommendations and dietary styles: Germany as an example. Environmental Science and Technology, 47(2), 877-888.

Milner, J., Green, R., Dangour, A. D., Haines, A., Chalabi, Z., Spadaro, J., Markandya, A., \& Wilkinson, P. (2015). Health effects of adopting low greenhouse gas emission diets in the UK. BMJ Open, 5, e007364.

Payne, C. L., Scarborough, P., \& Cobiac, L. (2016). Do low-carbon-emission diets lead to higher nutritional quality and positive health outcomes? A systematic review of the literature. Public Health Nutrition, 19(14), 2654-2661.

Perignon, M., Masset, G., Ferrari, G., Barr, T., Vieux, F., Maillot, M., Amiot, M.-J., \& Darmon, N. (2016). How low can dietary greenhouse gas emissions be reduced without impairing nutritional adequacy, affordability and acceptability of the diet? A modelling study to guide sustainable food choices. Public Health Nutrition, 19(14), 2662-2674.

Perignon, M., Vieux, F., Soler, L.-G., Masset, G., \& Darmon, N. (2017). Improving diet sustainability through evolution of food choices: Review of epidemiological studies on the environmental impact of diets. Nutrition Reviews, 75(1), 2-17.

Risku-Norja, H., Kurppa, S., \& Helenius, J. (2009). Dietary choices and greenhouse gas emissions assessment of impact of vegetarian and organic options at national scale. Progress in Industrial Ecology an International Journal, 6(4), 340-354.

Roos, E., Karlsson, H., Witthoft, C., \& Sundberg, C. (2015). Evaluating the sustainability of diets combining environmental and nutritional aspects. Environmental Science \& Policy, 47(Supplement C), 157-166.

Samuelson, P. (1951). Theory of optimal taxation. Re-printed in Journal of Public Economics (1986), 30, $137-143$.

Saxe, H., Larsen, T. M., \& Mogensen, L. (2013). The global warming potential of two healthy Nordic diets compared with the average Danish diet. Climatic Change, 116(2), 249-262. 
Scarborough, P., Allender, S., Clarke, D., Wickramasinghe, K., \& Rayner, M. (2012). Modelling the health impact of environmentally sustainable dietary scenarios in the UK. European Journal of Clinical Nutrition, 66, 710-715.

Searchinger, T., Heimlich, R., Houghton, R. A., Dong, F., Elobeid, A., Fabiosa, J., Tokgoz, S., Hayes, D., \& $\mathrm{Yu}, \mathrm{T}$. (2008). Use of US croplands for biofuels increases greenhouse gases through emissions from landuse change. Science, 319(5867), 1238-1240.

Springmann, M., Godfray, H. C. J., Rayner, M., \& Scarborough, P. (2016a). Analysis and valuation of the health and climate change co-benefits of dietary change. Proceedings of the National Academy of Sciences, 113(15), 4146-4151.

Springmann, M., Mason-DCroz, D., Robinson, S., Wiebe, K., Godfray, H. C. J., Rayner, M., \& Scarborough, P. (2016b). Mitigation potential and global health impacts from emissions pricing of food commodities. Nature Climate Change, 7, 69-74. https://doi.org/10.1038/nclimate3155.

Tol, R. (2012). A cost-benefit analysis of the EU 20/20/2020 package. Energy Policy, 49, 288-295.

Traill, B., Mazzocchi, M., Nied'zwiedzka, B., Shankar, B., \& Wills, J. (2013). The Eatwell project: Recommendations for healthy eating policy interventions across Europe. Nutrition Bulletin, 38(3), 352357.

Treich, N. (2015). La valeur de la vie humaine en économie. Futuribles, 404, 63-73.

Tukker, A., Goldbohm, R. A., de Koning, A., Verheijden, M., Kleijn, R., Wolf, O., Perez-Dominguez, I., \& Rueda-Cantuche, J. M. (2011). Environmental impacts of changes to healthier diets in Europe. Ecological Economics, 70(10), 1776-1788.

van Dooren, C., \& Aiking, H. (2016). Defining a nutritionally healthy, environmentally friendly, and culturally acceptable low lands diet. The International Journal of Life Cycle Assessment, 21(5), 688-700.

van Dooren, C., Marinussen, M., Blonk, H., Aiking, H., \& Vellinga, P. (2014). Exploring dietary guidelines based on ecological and nutritional values: A comparison of six dietary patterns. Food Policy, 44, 36-46.

Vieux, F., Darmon, N., Touazi, D., \& Soler, L. (2012). Greenhouse gas emissions of self-selected individual diets in France: Changing the diet structure or consuming less? Ecological Economics, 75, 91-101.

Vieux, F., Soler, L., Touazi, D., \& Darmon, N. (2013). High nutritional quality is not associated with low greenhouse gas emissions in self-selected diets of French adults. American Journal of Clinical Nutrition, 97, 569-583.

Vieux, F., Perignon, M., Gazan, R., \& Darmon, N. (2018). Dietary changes needed to improve diet sustainability: Are they similar across Europe? European Journal of Clinical Nutrition, 72, 951-960.

Westhoek, H., Lesschen, J. P., Rood, T., Wagner, S., Marco, A. D., Murphy-Bokern, D., Leip, A., van Grinsven, H., Sutton, M. A., \& Oenema, O. (2014). Food choices, health and environment: Effects of cutting Europe's meat and dairy intake. Global Environmental Change, 26, 196-205.

WHO. (2010). Global status report on non-communicable diseases (176 pp). Geneva: World Health Organization.

Zamagni, A., Guinee, J., Heijungs, R., Masoni, P., \& Raggi, A. (2012). Lights and shadows in consequential LCA. The International Journal of Life Cycle Assessment, 17(7), 904-918.

Publisher's note Springer Nature remains neutral with regard to jurisdictional claims in published maps and institutional affiliations. 